\title{
Claves de identificación macroscópica de la madera de 110 especies del Caribe Norte de Costa Rica
}

\section{Resumen}

La región Caribe Norte de Costa Rica abastece aproximadamente el $14 \%$ del mercado nacional de la madera, usando alrededor de 165 especies arbóreas. Sin embargo, dicha región carece de instrumentos que contribuyan a identificar las especies maderables; lo cual podría ayudar a que la administración forestal del Estado ejerza un mejor control. Ante tal escenario, el presente trabajo desarrolla un manual para la identificación de la madera en términos macroscópicos de 110 especies forestales de la región antes citada. Se describen las características generales y anatómicas de cada una de las especies. Dicha información se utilizó para construir dos tipos de claves de identificación: once claves gráficas que describen los criterios de clasificación para los principales caracteres anatómicos y que permiten encausar la identificación de cada especie, y una clave dicotómica basada en un carácter anatómico, el cual es utilizado como criterio de clasificación en dos

\section{Abstract}

Key wood macroscopic identification of 110 species Northern Caribbean of Costa Rica.

The Northern region of Costa Rica Caribbean supplies approximately $14 \%$ of the wood market, using about 165 species. However this region lacks an instrument to help identify wood species, which could help to forest control to the Costa Rica's Government. According to the objective of this paper is to develop a wood key identification using macroscopic wood features of 110 species of Northern Caribbean forest. Initially it was described the general characteristics and macroscopic features of each of species. This information was used to build two kind of wood identification keys. The first identification key is presented in graphical form through eleven keys, which describes the main anatomical classification topic and allow species wood identification. The second identification key is a wood dicotomic key, 
respuestas. Estos recursos están dirigidos a facilitar las labores de identificación tanto del personal de campo, como de los técnicos especializados en diversidad biológica y conservación, entre otros.

Palabras clave: anatomía de la madera, maderas tropicales, clave de identificación, Caribe Norte, Área de Conservación Tortuguero, Costa Rica.

\section{Introducción}

De acuerdo con SINAC (2011), en la primera década de este siglo, el Área de Conservación Tortuguero ocupó el segundo puesto en la extracción de árboles bajo la modalidad de plan de manejo y el tercero en la extracción de árboles en terrenos de uso agropecuario y sin bosque. Las estadísticas de otorgamiento de permisos del año 2007 al 2011 apuntan a que durante ese periodo se autorizó la corta de al menos 165 especies forestales para el aprovechamiento forestal, de las cuales, solo diez especies figuran como especies exóticas (ACTo 2006).

Dada la gran variabilidad en el uso de especies autóctonas para el aprovechamiento forestal en esa área, resultan de gran importancia los esfuerzos orientados a generar capacidades para el conocimiento y la identificación de las mismas. Actualmente, existen publicaciones que facilitan la identificación de árboles para Costa Rica considerando sus características dendrólogicas (Holdridge \& Poveda 1975; Zamora et al. 2003); y se dispone además, de otras herramientas digitales en internet, tales como "La Flora Digital de La Selva" (OET 2004), que además de ofrecer colecciones de fotos de un gran número de especies que crecen en el Caribe Norte de Costa Rica, brinda acceso a claves electrónicas dicotómicas para aproximadamente 30 familias, basadas en las características dendrológicas.

No obstante, las herramientas antes mencionadas son de poca ayuda cuando los árboles ya han sido cortados y extraídos de su entorno natural, debido a la escasa o nula presencia de los caracteres dendrológicos que definen a cada especie. Esta dificultad también limita la capacidad de las autoridades ambientales para la supervisión de las especies forestales autorizadas en los permisos de aprovechamiento, ya sea en los centros de aserrío o comercio de madera, o bien, en los operativos de control dirigidos a la detección de madera de procedencia ilegal.

Ante este problema se han desarrollado otro tipo de técnicas donde la base de identificación de las especies es la anatomía de la madera. En Costa Rica, algunos han realizado esfuerzos tendientes a generar manuales para la identificación de especies a partir de su madera. where anatomy features is used as a sorting criterion in two responses. These wood keys identification could be facilitate wood identification by forest guard.

Key words: wood anatomy, tropical woow, identification key, North Caribbean, Tortuguero Conservation Area, Costa Rica.

Por ejemplo, Acosta (1967), realizó una descripción anatómica para 25 especies colectadas en su totalidad en la Reserva Forestal Río Macho. Por su parte, Jaen (1989) desarrolló un manual para la identificación de algunas especies maderables amenazadas o en peligro de extinción de la Península de Osa en Costa Rica, circunscribiéndose a un grupo de 15 especies. Finalmente, uno de los esfuerzos más ambiciosos en la generación de herramientas para la identificación de maderas lo llevó a cabo Wiemann (1987), quién desarrolló para la identificación de aproximadamente 149 especies de todo el país, con la particularidad de que consideró 29 especies exóticas, y está basada en aspectos macroscópicos y microscópicos.

No obstante, para la región del Caribe Norte de Costa Rica, no existen manuales para la identificación de especies a nivel de madera, por lo que el presente trabajo tiene como objetivo el desarrollar guías (esquemática y dicotómica) para la identificación a nivel macroscópico de 110 especies de maderas utilizadas en el Caribe Norte de Costa Rica. De esta manera, este trabajo se constituye así en un esfuerzo novedoso que tiene como propósito primordial brindar a las personas que lo utilizan, una herramienta de consulta que facilite la identificación de las maderas.

\section{Materiales y métodos}

\section{Área de estudio}

El Área de Conservación Tortuguero (ACTo), se localiza en la región del Caribe Noreste costarricense y tiene una extensión terrestre aproximada de 302481 hectáreas $\left(3024 \mathrm{Km}^{2}\right)$. Presenta una topografía muy regular, con altitudes que oscilan entre los 0 y $1350 \mathrm{msnm}$, con una precipitación promedio anual de $6000 \mathrm{~mm}$ (Mora \& Román 2006). De acuerdo con Bolaños y Watson (1999), esta región presenta cinco de las zonas de vida de Holdridge: el bosque muy húmedo tropical, el bosque pluvial premontano, transición a basal; el bosque muy húmedo tropical, transición a premontano; el bosque pluvial premontano y el bosque muy húmedo premontano, transición a basal. 


\section{Selección de especies}

Para seleccionar las especies descritas en el presente estudio se procedió a gestionar un reporte de especies autorizadas para la corta, con base en el sistema de estadísticas de permisos del Área de Conservación Tortuguero para los años 2009 - 2011 (ACTo 2011). Este reporte arrojó una lista de 165 especies que tuvo que ser depurada, procediéndose a excluir las especies introducidas al país, así como aquellas que no se reportan para la zona y que probablemente fueron identificadas o consignadas erróneamente en la base de datos. Posteriormente esta lista se cotejó con la disponibilidad de especies de la xiloteca "Victor Rojas" de la Escuela de Ingeniería Forestal (TECw) del Instituto Tecnológico de Costa Rica (Llynch \& Gasson 2010). En esta comparación fueron seleccionadas 110 especies, donde se incluyeron especies vedadas por el Decreto Ejecutivo 25700-MINAE (MINAE 1997).

\section{Preparación de muestras}

De las muestras seleccionadas se obtuvo un bloque de $1 \times 1 \times 1 \mathrm{~cm}$, con los planos longitudinal, tangencial y radial debidamente orientados para proceder a realizar la descripción general y macroscópica correspondiente. En la descripción general, se utilizó las muestras de la xiloteca, con dimensiones de $14 \mathrm{~cm}$ de largo, $7 \mathrm{~cm}$ de ancho y $1,2 \mathrm{~cm}$ de espesor.

\section{Descripción general}

Las propiedades generales determinadas fueron: color, brillo, olor, sabor, textura, dirección del grano, veteado y densidad de la madera. Para aquellas muestras que evidenciaban la presencia de albura y duramen, la determinación de color se hizo en forma separada para la albura y el duramen por medio de las tablas de color de Munsell para suelos (Mac Corporation1994). Aquellas muestras que no evidenciaban diferenciación de albura y duramen, solo se les consignó un color para ambos tipos de madera. Para la descripción de madera se utilizó los criterios de la Comisión Pan-Americana de Normas Técnicas-COPANT (COPANT 1974) y las "Normas e Procedimentos em Estudos da Anatomía da Madeira" (IBAMA 1992).

\section{Descripción macroscópica}

A cada bloque de $1 \times 1 \times 1 \mathrm{~cm}$ y con la ayuda de una hoja de corte de un micrótomo se procedió a realizar cortes finos en sentido paralelo a la sección transversal hasta una superficie limpia (Gonzales 2008). Luego se le humedeció con agua con el fin de lograr un mayor contraste entre las estructuras anatómicas de la madera, especialmente a nivel de parénquima.

La descripción macroscópica se basó en la determinación de una serie de características anatómicas de la lista propuesta por la Asociación Internacional de Anatomistas de la Madera (IAWA 1989) para la identificación microscópica de maderas duras observables con un aumento de 10X, considerándose además los términos propuestos por Espinoza y León (2001), los criterios de la Comisión Pan-Americana de Normas TécnicasCOPANT (COPANT 1974) y las Normas y Procedimientos en Estudios de Anatomía de Madera (IBAMA 1992).

La observación de la madera se realizó con la ayuda de una lupa con aumento de 10X y en cada muestra se estudiaron los vasos, parénquima, radios y formación de anillos de crecimiento catalogados de la siguiente manera:

1. Poros: se determinó la presencia o ausencia, su tamaño de acuerdo a la visibilidad con aumento de $10 \mathrm{X}$ (visibles a simple vista, visibles con aumento de 10X y poco visibles o distinguibles con aumento de 10X) y se clasificó en grandes, medianos y pequeños; se observó el agrupamiento de los poros (solitarios, biseriados, múltiples y en aglomerados); se clasificó la abundancia en escasos, medianamente abundantes, abundantes y muy abundantes; se clasificó el tipo de porosidad (difusa o semianular) y la tendencia presente en la distribución de los poros (tendencia a formar bandas tangenciales, líneas radiales o diagonales, patrón déndrico o sin patrón definido) y finalmente, se catalogó la presencia de sustancias dentro de poros según su naturaleza (tílides, gomas, tílides y gomas presentes en duramen y sin presencia de sustancias en los poros).

2. Parénquima axial: se evaluó el grado de visibilidad; la presencia o ausencia deeste, con baseen la diferenciación en los tonos del color alrededor de los vasos o en general la sección transversal de la muestra en estudio. Esta diferenciación de color permitió definir los tipos de parénquima: paratraqueal, apotraqueal y en bandas. En el parénquima paratraqueal se establecieron las siguientes categorías: escaso, vasicéntrico, unilateral, aliforme que puede ser de alas finas o gruesas y aliforme confluente. El parénquima apotraqueal fue categorizado como apotraqueal difuso y en agregados. El parénquima en bandas se clasificó como bandas abundantes o escasas, finas o gruesas, marginales, escaleriformes o reticulada.

3. Parénquima radial: sobre la sección transversal se determinó si eran visibles o no, la existencia de radios de un solo ancho o de dos o más, el tamaño de éstos (finos, medios o grueso), la frecuencia (escasamente abundantes, medianamente abundantes, abundantes y muy abundantes). Posteriormente, en el plano tangencial, se observó si se presentaban estratificados o no estratificados.

4. Otras estructuras anatómicas: en la observación de la madera también se estableció si existían otros elementos anatómicos observados a nivel macroscópico, tal como la presencia de floema incluso, conductos gomíferos o canales traumáticos. 


\section{Resultados}

Con la información anatómica de todas las especies fueron construidas las claves de identificación, que se detallan a continuación: (i) Claves de identificación esquemáticas: generadas a partir de una clave maestra y diseñada para el uso generalizado a nivel de campo, por personal técnico con un nivel básico de capacitación; (ii) Clave de identificación dicotómica: dirigida a personas con un mayor grado de especialización en el uso de claves de identificación. Tanto la clave de identificación esquemática como la dicotómica se construyeron a partir de los reportes generados en la descripción de la madera. Se propuso un esquema de clasificación que inicia por separar las especies según el tipo de porosidad, el agrupamiento de los poros, el tamaño y la abundancia de poros, para luego separarlas especiessegúneltipode parénquima presente.

\section{Características generales}

Se encontró que el $51 \%$ de las especies analizadas presentaron algún grado en la marcación entre la albura y el duramen. Así mismo, se encontró que el $75,4 \%$ de las especies presentaron albura con tonalidades amarillas, mientras que solo un $45,4 \%$ de las especies presentaron duramen de esa coloración. Aproximadamente un 50 $\%$ de las especies presentaron duramen de coloración café $(32,7 \%)$ y rojizo (17,3\%). En lo referente al veteado se determinó que el $57,3 \%$ de las especies mostraron veteado en el corte tangencial. En cuanto a la textura, la categoría de textura media se presentó en el $73,6 \%$ de los casos, siendo la textura gruesa la menos presente, con un 20,1\%. El olor es una propiedad que distinguió a tan solo el $10 \%$ de las especies en condición seca, siendo muy característico para las especies Cedrela odorata y Carapa guianensis. Por su parte, el sabor distinguió a un grupo menor de especies llegando a tan solo el $4 \%$ de las analizadas. Sobresale nuevamente Cedrela odorata y se le agrega Goethalsia meiantha con presencia de un sabor amargo. Así mismo; se encontró un sabor astringente en la especie Macrohasseltia macroterantha. Con relación al brillo de la madera, se evidenció que la condición brillante fue la menos frecuente observándose en tan solo un 8,2 \% de los casos; siendo la condición de brillo medio la que se encontró en mayor porcentaje $(66,4 \%)$. En la marcación de los anillos, el 21,8 \% de las especies estudiadas presentaron esa característica. Finalmente, de las características generales de la madera, resulta notable que el $63,6 \%$ de las especies se clasificaron como de densidad media (de 0,45 a 0,70 $\mathrm{g} / \mathrm{cm}^{3}$ ) y el $20 \%$ de densidad alta (mayor a $0,70 \mathrm{~g} / \mathrm{cm}^{3}$ ).

\section{Características macroscópicas}

Poros: Como todas las especies evaluadas son latifoliadas, este elemento anatómico estuvo presente en la totalidad de ellas. Se encontró que el $47,3 \%$ de las especies presentaron poros visibles a simple y en el $52,7 \%$ de las especies fue necesario contar con una lupa 10X ya que solo con este instrumento fueron visibles. Se evidenció que el $10 \%$ de las especiesmostraron presencia de poros exclusivamente solitarios, constituyéndose en un elemento que podría facilitar la determinación de especies como Calophyllum brasiliense y Humiriastrum diguense, entre otras. Además, existe un pequeño grupo de especies $(9,1 \%)$ que presentaron poros en aglomerados, también importante desde el punto de vista de identificación, como el caso de Mouriri sp y Theobroma simiarum.

Se observó que solo siete especies de las estudiadas tenían porosidad semianular, siendo esta característica más evidente para la especie Cedrela odorata. En las restantes seis especies, no se tuvocerteza de que esa condición fuera intrínseca, o bien, pudo ser inducida por las condiciones ambientales. Así mismo, pesar que el 99 $\%$ de las especies estudiadas presentaron porosidad difusa, se encontró que el $11,8 \%$ presentaron tendencia a conformarbandastangenciales, comoel caso deErythrina poeppigiana, y líneas radiales o diagonales en el 26,4 $\%$, como en Couma macrocarpa y Dipterix panamensis. Finalmente el $62,7 \%$ de las especies no presentaron ningún tipo de patrón en la distribución de los poros. Otro elemento que contribuyó a caracterizar un importante grupo de especies fue la presencia de sustancias como tílides y gomas, asociados a los vasos, condición que se encontró que en el 49,1 \% de las especies, entre ellas Brosimum alicastrum y Lonchocarpus ferrugineus.

Parénquima axial: Este elemento anatómico fue común en el $93,6 \%$ de los casos estudiados. El 35,4\% de las especies presentaron parénquima apotraqueal, el $84,5 \%$ presentaron parénquima paratraqueal y el $60 \%$ presentó parénquima en forma de bandas, pudiéndose encontrar hasta los tres tipos de parénquima en forma simultánea en el $18,2 \%$ de las especies estudiadas, entre ellas Apeiba membranacea. El parénquima paratraqueal más observado fue el parénquima vasicéntrico $(45,4 \%)$, escaso $(36,4 \%)$ y aliforme confluente $(36,4 \%)$, mientras que el menos común fue el parénquima unilateral presente en combinación con otros tipos de parénquima en menos del $10 \%$ de los casos observados, como en Brosimum costaricanum. La presencia de bandas reticuladas y escaleriformes se observó en el 15,4\% de las especies, facilitando el proceso de identificación de Goethalsia meiantha y Lecythis ampla, entre otras.

Parénquima radial: La presencia de radios de dos gruesos es común solo en el $20 \%$ de las especies, como Pachira aquatica. Otra característica particular de los radios es la estratificación, se presentó en el 19,1 $\%$ de las especies estudiadas, permitiendo identificar a Dussia cuscatlanica e Hymenolobium mesoamericanum.

Otras estructuras anatómicas: Se evidenció que el 18,2 $\%$ de las especies presentaron otro tipo de estructuras 
anatómicas visibles con aumento de 10X. Por ejemplo, Theobroma simiarum mostró presencia de canales axiales que formaron bandas tangenciales, mientras que en Tetragastris panamensis se observaron canales radiales, Virola koschnyi presentó tubos laticíferos o taniníferos; y Vochysia ferruginea evidenció la presencia de canales intercelulares de origen traumático.

\section{Esquema de identificación de especies}

Basado en la descripción de la madera de todas las especies, se construyó la clave de identificación. En las figura 1 se presenta la clave maestra que resume el esquema implementado para la identificación del grupo de análisis. Esta clave maestra define los criterios de clasificación utilizados, y a partir de ella, se originaron diez sub-claves de identificación (Figuras 2 a la 10). Primeramente se plantea como criterio de clasificación la porosidad, separando las especies con porosidad semicircular (Figura 2) de las especie con porosidad difusa. Posteriormente, el grupo de especies con porosidad difusa se clasificó por el agrupamiento de los poros, encontrándose 11 especies con presencia de poros exclusivamente solitarios (Figura 3) y por otro 91 especies con presencia de poros solitarios y múltiples. Seguidamente, el grupo de especies con poros solitarios y múltiples se clasificó por el tamaño de poro, generando tres grupos: un grupo de 38 especies con tamaño de poro pequeño; uno de 56 especies con tamaño de poro mediano y uno de 19 especies con tamaño de poro grande. El grupo de especies con poros de tamaño pequeño se clasificó, a su vez, por la abundancia de los poros: subclave de poros escasamente abundantes (Figura 4), otra para poros medianamente abundantes (Figura 5) y otra para poros abundantes y muy abundantes (Figura 6). Ese mismo ejercicio de clasificación se realizó para el grupo de especies con poros de tamaño mediano, dando como resultados las sub-claves de identificación mostradas en las Figuras 7, 8 y 9 . Finalmente, las especies con presencia de poros grandes se clasificaron en una sub-clave para especies con estratificación presente (Figura 10) y otra para especies con estratificación ausente (Figura 11).

\section{Clave dicotómica de identificación}

La clave dicotómica de identificación está construida bajo los mismos criterios de clasificación usados para la clave de identificación esquemática. Primeroseclasificóalasespecies con porosidad semicircular de aquellas con porosidad difusa. Las especies de porosidad difusa se segregan en las que presentaron poros exclusivamente solitarios de las poseen poros solitarios y múltiples. Finalmente se clasificaron las especies resultantes por el tamaño de poro en pequeño, mediano y grande. Las especies con poros pequeños y medianos fueron sub-divididas por la abundancia de los poros; mientras que las especies con poros grandes fueron clasificadas por la presencia o ausencia de estratificación. 
Cuadro 1. Claves de identificación macroscópica de la madera de especies del Caribe Norte de Costa Rica.

\begin{tabular}{|c|c|c|}
\hline $1 a$ & Porosidad semicircular & $2 a$ \\
\hline $1 \mathrm{~b}$ & Porosidad difuso & $6 a$ \\
\hline $2 a$ & Parénquima apotraqueal difuso y en agregados & $3 a$ \\
\hline $2 b$ & Parénquima paratraqueal con o sin presencia de bandas & $5 a$ \\
\hline 3a & Ausencia de bandas de parénquima & Ochroma pyramidale \\
\hline $3 b$ & Presencia de bandas aparentemente marginales & $4 a$ \\
\hline $4 a$ & Madera café rojiza con fuerte sabor amargo & Cedrela odorata \\
\hline $4 \mathrm{~b}$ & Madera café, veteada de textura media fina con olor agradable & Cordia alliodora \\
\hline $4 c$ & Madera café pálido con gomas de peso moderado & Vitex cooperi \\
\hline $5 a$ & Parénquima vasicéntrico y losangular con bandas reticuladas & Erythrina poeppigiana \\
\hline $5 b$ & Parénquima aliforme y confluente con bandas finas y gruesas & Terminalia amazonia \\
\hline $5 c$ & Solo parénquima vasicéntrico escaso, madera amarillenta & Nectandra sinuata \\
\hline $6 a$ & Poros exclusivamente solitarios & $7 a$ \\
\hline $6 b$ & Poros solitarios y múltiples & $13 a$ \\
\hline $7 a$ & Poros grandes & $8 a$ \\
\hline $7 \mathrm{~b}$ & Poros medianos & $9 a$ \\
\hline $7 c$ & Poros pequeños & $11 \mathrm{a}$ \\
\hline $8 a$ & Parénquima aliforme y losangular con bandas gruesas & Jacaranda copaia \\
\hline $8 b$ & Parénquima paratraqueal escaso con bandas finas & Maranthes panamensis \\
\hline $9 a$ & Parénquima apotraqueal difuso presente & $10 a$ \\
\hline $9 b$ & Poros con gomas forman cadenas radiales y diagonales & Calophyllum brasiliense \\
\hline $10 \mathrm{a}$ & Parénquima paratraqueal ausente, madera café y pesada & Hieronyma alchorneoides \\
\hline $10 \mathrm{~b}$ & Parénquima paratraqueal vasicéntrico, madera rojiza y pesada & Aspidosperma spruceanum \\
\hline $11 \mathrm{a}$ & Poros pequeños con estratificación ausente & $12 a$ \\
\hline $11 b$ & Poros pequeños con estratificación presente & Sacoglottis trichogyna \\
\hline $12 \mathrm{a}$ & Bandas escaleriformes y finas discontinúas, madera amarilla pesada & Licania hypoleuca \\
\hline $12 b$ & Poros abundantes con tílides, madera pesada & Vantanea barbourii \\
\hline $12 \mathrm{c}$ & Parénquima paratraqueal ausentecon gomas en los vasos & Humiriastrum diguense \\
\hline $12 d$ & Parénquima apotraqueal difuso y en agregados, olor a pejibaye & Maranthes panamensis \\
\hline $12 e$ & Poros forman cadenas radiales de 2-8 vasos Bandas finas & Mouriri gleasoniana \\
\hline $12 f$ & Parénquima aliforme y losangular Poros forman cadenas diagonales cortas & Mouriri sp \\
\hline $13 a$ & Poros pequeños escasamente abundantes & $14 a$ \\
\hline $13 b$ & Poros pequeños medianamente abundantes & $16 a$ \\
\hline $13 c$ & Poros pequeños abundantes y muy abundantes & $29 a$ \\
\hline $13 d$ & Poros medianos escasamente abundantes & $41 a$ \\
\hline $13 e$ & Poros medianos de abundancia media & $46 a$ \\
\hline $13 f$ & Poros medianos abundantes y muy abundantes & $62 a$ \\
\hline
\end{tabular}




\begin{tabular}{|c|c|c|}
\hline $13 g$ & Poros grandes con estratificación de radios presente & $69 a$ \\
\hline $13 \mathrm{~h}$ & Poros grandes sin estratificación de radios & $71 \mathrm{a}$ \\
\hline $14 a$ & Estratificación presente & $15 a$ \\
\hline $14 b$ & Estratificación ausente & Quararibea asterolepis \\
\hline $15 a$ & Parénquima paratraqueal confluente y aliforme losangular & Dussia macroprophyllata \\
\hline $15 b$ & Parénquima paratraqueal confluente & Dussia cuscatlanica \\
\hline $16 a$ & Estratificación presente & $17 a$ \\
\hline $16 b$ & Estratificación ausente & $18 a$ \\
\hline $17 \mathrm{a}$ & Parénquima paratraqueal confluente y aliforme losangular & Dussia macroprophyllata \\
\hline $17 \mathrm{~b}$ & Parénquima paratraqueal confluente & Dussia cuscatlanica \\
\hline $18 a$ & Parénquima axial ausente o extremadamente raro & $19 a$ \\
\hline $18 \mathrm{~b}$ & Parénquima axial presente & $22 a$ \\
\hline $19 a$ & Radios de un solo ancho & $20 a$ \\
\hline $19 b$ & Radios de dos anchos & $21 a$ \\
\hline $20 a$ & Radios de tamaño y abundancia media Peso moderado & Laetia procera \\
\hline $20 \mathrm{~b}$ & Radios finos muy abundantes Sabor astringente & Macrohasseltia macroterantha \\
\hline $21 a$ & Poros solitarios y múltiples 2-6 Radios finos muy abundantes & Hasseltia floribunda \\
\hline $21 b$ & Poros múltiples 2-3 Radios finos y medios & Sloanea medusula \\
\hline $22 \mathrm{a}$ & Parénquima apotraqueal difuso o en agregados & $23 a$ \\
\hline $22 b$ & Parénquima paratraqueal con o sin bandas & $24 a$ \\
\hline $23 a$ & Madera rojiza con bandas escaleriformes, presenta gomas & Couma macrocarpa \\
\hline $23 b$ & Madera amarilla con parénquima poco visible & Ilex skutchii \\
\hline $23 c$ & Parénquima vasicéntrico, losangular, aliforme y confluente & Pentaclethra macroloba \\
\hline $24 a$ & Parénquima paratraqueal con bandas & $25 a$ \\
\hline $24 b$ & Parénquima paratraqueal sin bandas & $28 a$ \\
\hline $25 a$ & Bandas escaleriformes & $26 a$ \\
\hline $25 b$ & Bandas finas, gruesas y/o aparentemente marginales & $27 a$ \\
\hline $26 a$ & Madera pesada rojiza con anillos de crecimiento & Lecythis ampla \\
\hline $26 b$ & Madera pesada amarillacon tílides en vasos del duramen & Xylopia sericophylla \\
\hline $27 a$ & Parénquima paratraqueal confluente y losangular con gomas & Guarea rhopalocarpa \\
\hline $27 b$ & Poros múltiples 2-6 con bandas gruesas de parénquima & Pouteria sp \\
\hline $27 c$ & Parénquima aliforme y losangular con bandas delgadas & Symphonia globulifera \\
\hline $27 d$ & Parénquima vasicéntrico con bandas aparentemente marginales & Billia columbiana \\
\hline $28 a$ & Parénquima aliforme y losangular con bandas gruesas & Jacaranda copaia \\
\hline $28 b$ & Parénquima paratraqueal escaso con bandas finas & Maranthes panamensis \\
\hline
\end{tabular}




\begin{tabular}{|c|c|c|}
\hline $28 c$ & Parénquima paratraqueal escaso, madera amarilla con tílides escasas & Ocotea insularis \\
\hline $28 d$ & Madera café pálido con canales axiales en cadenas tangenciales & Theobroma simiarum \\
\hline $29 a$ & Estratificación presente, madera pesada color oliváceo & Tabebuia ochracea \\
\hline $29 b$ & Estratificación ausente & $30 a$ \\
\hline $30 a$ & Parénquima axial ausente o extremadamente raro & $31 a$ \\
\hline $30 b$ & Parénquima axial presente & $32 a$ \\
\hline $31 a$ & Poros forman cadenas tangenciales, madera amarilla & Laetia procera \\
\hline $31 b$ & Poros mayoritariamente solitarios, madera rosada & Sloanea faginea \\
\hline $31 c$ & Poros solitarios y múltiples $2-6$, radios finos muy abundantes & Hasseltia floribunda \\
\hline $32 a$ & Parénquima apotraqueal difuso y/o en agregados & $33 a$ \\
\hline $32 b$ & Parénquima paratraqueal y/o con bandas & $36 a$ \\
\hline $33 a$ & Presencia de bandas & $34 a$ \\
\hline $33 b$ & Ausencia de bandas & $35 a$ \\
\hline $34 a$ & Madera amarilla con radios de dos anchos evidentes en cara tangencial & llex skutchii \\
\hline $34 b$ & Madera amarilla, radios finos con canales de aceites longitudinal & Ocotea laetevirens \\
\hline $34 c$ & Madera amarilla con vetas y parénquima vasicéntrico & Zanthoxylum acuminatum \\
\hline $34 d$ & Madera pesada café amarillenta con vetas y de textura fina & Elaeoluma glabrescens \\
\hline $35 a$ & Madera blanquecina pesada con predominio de poros solitarios & Genipa americana \\
\hline $35 b$ & Parénquima vasicéntrico con canales de resina en sentido longitudinal & Tapirira myriantha \\
\hline $35 c$. & Madera amarilla pesada con radios de dos anchos & Grias cauliflora \\
\hline $36 a$ & Parénquima paratraqueal y/o con bandas & $37 a$ \\
\hline $36 b$ & Parénquima paratraqueal ausente con bandas & $40 a$ \\
\hline $37 a$ & Radios de ancho fino & $38 a$ \\
\hline $37 b$ & Radios de ancho medio y grueso & $39 a$ \\
\hline $38 a$ & Poros solitarios mayoritariamente con bandas reticuladas & Licania platypus \\
\hline $38 b$ & Madera rosada con canales en sentido radial y longitudinal & Tetragastris panamensis \\
\hline $38 \mathrm{c}$ & Poros ovalados con radios finos muy abundantes y gomas & Sclerolobium costarricense \\
\hline $39 a$ & Madera amarilla con poros que tienden a formar cadenas tangenciales & Laetia procera \\
\hline $39 b$ & Parénquima vasicéntrico, aliforme, confluente y unilateral & Brosimum alicastrum \\
\hline $39 c$ & Parénquima vasicéntrico escaso, madera amarilla de peso moderado & Nectandra sinuata \\
\hline $39 d$ & Madera amarilla y pesada Radios gruesos de abundancia media & Chimarrhis parviflora \\
\hline $40 a$ & Madera amarilla pesada, veteada, con bandas finas y reticuladas & Chrysophyllum cainito \\
\hline $40 \mathrm{~b}$ & Madera rojiza pesada ligeramente veteada con bandas reticuladas & Manilkara chicle \\
\hline $41 a$ & Parénquima apotraqueal difuso y/o en agregados & $42 a$ \\
\hline $41 b$ & Parénquima paratraqueal y/o con bandas & $45 \mathrm{a}$ \\
\hline $42 a$ & Radios de un solo ancho & $43 a$ \\
\hline
\end{tabular}




\begin{tabular}{|c|c|c|}
\hline $42 b$ & Radios de dos anchos & $44 a$ \\
\hline $43 a$ & Madera liviana con parénquima en agregados similar a patrón escaleriforme & Sapium sp \\
\hline $43 b$ & Parénquima escaso con bandas escaleriformes, finas y gruesas & Goethalsia meiantha \\
\hline $43 c$ & Parénquima escaso con bandas gruesas y aparentemente marginales & Ceiba pentandra \\
\hline $44 a$ & Parénquima vasicéntrico con radios medios y gruesos & Mortoniodendron anisophyllum \\
\hline $44 \mathrm{~b}$ & Madera amarillo pálido liviana con radios finos y medios & Ochroma pyramidale \\
\hline $44 \mathrm{c}$ & Parénquima paratraqueal ausente con bandas reticuladas & Quararibea cordata \\
\hline $44 d$ & Radios medios y gruesos visibles en cara tangencial & Sterculia costaricana \\
\hline $45 a$ & Madera muy liviana con bandas gruesas discontinuas & Heliocarpus appendiculatus \\
\hline $45 b$ & Madera amarilla liviana con bandas reticuladas & Erythrina poeppigiana \\
\hline $45 c$ & Parénquima vasicéntrico, aliforme, losangular y confluente & Hernandia didymantha \\
\hline $45 d$ & Poros múltiples 2 dominantemente, madera amarilla de peso moderado & Trichillia sp \\
\hline $45 e$ & Madera rosada, pesada de textura fina & Inga alba \\
\hline $46 a$ & Estratificación presente & $47 a$ \\
\hline $46 \mathrm{~b}$ & Estratificación ausente & $50 a$ \\
\hline $47 a$ & Parénquima apotraqueal difuso y en agregados & Luehea seemannii \\
\hline $47 \mathrm{~b}$ & Parénquima paratraqueal y/o con bandas & $48 a$ \\
\hline $48 a$ & Presencia de tílides y/o gomas & $49 a$ \\
\hline $48 b$ & Ausencia de tílides y/o gomas & Dussia cuscatlanica \\
\hline $49 a$ & Madera rojiza pesada con bandas anchas muy visibles a simple vista & Andira inermis \\
\hline $49 b$ & Madera café, liviana con parénquima vasicéntrico dominante & Enterolobium cyclocarpum \\
\hline $49 c$ & Parénquima vasicéntrico con bandas discontinuas y gruesas & Lonchocarpus ferrugineus \\
\hline $49 d$ & Parénquima vasicéntrico con bandas gruesas y continuas & Lonchocarpus macrophyllus \\
\hline $49 e$ & Parénquima confluente, losangular con bandas marginales & Ormosia coccinea \\
\hline $49 f$ & Parénquima vasicéntrico, madera rosada, peso medio & Stryphnodendron microstachyum \\
\hline $50 a$ & Parénquima paratraqueal con o sin presencia de bandas & $51 a$ \\
\hline $50 b$ & Parénquima apotraqueal difuso y difuso en agregados & $58 a$ \\
\hline $51 a$ & Presencia de bandas & $53 a$ \\
\hline $51 b$ & Ausencia de bandas & $57 a$ \\
\hline $52 a$ & Bandas reticuladas y/o escaleriformes & $53 a$ \\
\hline $52 b$ & Bandas finas, gruesas y aparentemente marginales & $54 a$ \\
\hline $53 a$ & Poros múltiples 2-6, madera amarilla pesada & Xylopia sericophylla \\
\hline $53 b$ & Parénquima aliforme de alas cortas, madera liviana & Rollinia pittieri \\
\hline $53 c$ & Madera amarillenta de peso moderado con gomas naranja & Clarisia mexicana \\
\hline $53 d$ & Parénquima paratraqueal ausente, oxidación grisácea a negra & Hernandia stenura \\
\hline $53 e$ & Madera amarilla liviana con bandas reticuladas & Erythrina poeppigiana \\
\hline $54 a$ & Presencia de tílides & $55 a$ \\
\hline $54 b$ & Ausencia de tílides & $56 a$ \\
\hline
\end{tabular}




\begin{tabular}{|c|c|c|}
\hline $55 a$ & Parénquima escaso, aliforme, confluente con bandas marginales & Guarea sp \\
\hline $55 b$ & Parénquima vasicéntrico y escaso con tubos laticíferos & Virola sebifera \\
\hline $55 c$ & Parénquima aliforme y confluente con bandas finas & Symphonia globulifera \\
\hline $55 d$ & Poros solitarios dominantes Madera café pálida, pesada & Terminalia bucidoides \\
\hline $56 a$ & Parénquima vasicéntrico confluente con bandas gruesas & Castilla elastica \\
\hline $56 b$ & Parénquima vasicéntrico con bandas aparentemente marginales & Cordia bicolor \\
\hline $56 c$ & Parénquima aliforme, losangular, con bandas finas y marginales & Pourouma bicolor \\
\hline $56 d$ & Parénquima aliforme y confluente con bandas finas continúas & Ruptiliocarpon caracolito \\
\hline $56 e$ & Madera amarillenta con vetas de textura fina y peso moderado & Terminalia amazonia \\
\hline $57 a$ & Madera liviana Poros con tendencia a formar líneas diagonales & Trema integerrima \\
\hline $57 b$ & Parénquima vasicéntrico, aliforme, losangular y unilateral & Poulsenia armata \\
\hline $57 \mathrm{c}$ & Parénquima aliforme, losangular, confluente y unilateral & Brosimum costaricanum \\
\hline $57 d$ & Madera café, liviana y parénquima vasicéntrico dominante & Enterolobium cyclocarpum \\
\hline $57 e$ & Parénquima vasicéntrico, madera rosada, peso medio & Stryphnodendron microstachyum \\
\hline $57 f$ & Parénquima vasicéntrico escaso, radios finos de abundancia media & Nectandra reticulata \\
\hline $58 a$ & Parénquima apotraqueal sin bandas & Mortoniodendron anisophyllum \\
\hline $58 b$ & Parénquima apotraqueal con bandas & $59 a$ \\
\hline $59 a$ & Radios de dos anchos & $60 a$ \\
\hline $59 b$ & Radios un solo ancho & $61 a$ \\
\hline $60 a$ & Parénquima vasicéntrico, aliforme de alas cortas y confluente & Sterculia apetala \\
\hline $60 \mathrm{~b}$ & Bandas aparentemente marginales con poros en aglomerados & Sterculia costaricana \\
\hline $61 \mathrm{a}$ & Madera café rojiza pesada con tílides y gomas oscuras & Pentaclethra macroloba \\
\hline $61 b$ & Madera café amarillenta con presencia de canales de resina & Prioria copaifera \\
\hline $61 c$ & Parénquima escaso con bandas gruesas y aparentemente marginales & Ceiba pentandra \\
\hline $62 \mathrm{a}$ & Estratificación presente & $63 a$ \\
\hline $62 \mathrm{~b}$ & Estratificación ausente & $64 a$ \\
\hline $63 a$ & Madera rojiza pesada con bandas finas sin distribución regular & Dipteryx panamensis \\
\hline $63 b$ & Madera blanco grisácea de peso moderado y bandas marginales & Tabebuia rosea \\
\hline $63 c$ & Madera amarilla, pesada y bandas aparentemente marginales & Lonchocarpus oliganthus \\
\hline $63 d$ & Parénquima vasicéntrico con bandas aparentemente marginales & Swietenia macrophylla \\
\hline $63 e$ & Parénquima vasicéntrico dominante, madera amarilla pesada & Abarema macradenia \\
\hline $64 a$ & Parénquima apotraqueal difuso y en agregados & $65 a$ \\
\hline $64 b$ & Parénquima paratraqueal o apotraqueal con o sin presencia de bandas & $66 a$ \\
\hline $65 a$ & Parénquima vasicéntrico con bandas muy gruesas marginales & Apeiba membranacea \\
\hline $65 b$ & Madera amarilla liviana con tílides abundantes & Hura crepitans \\
\hline $65 c$ & Parénquima apotraqueal tiende a formar patrón escaleriforme & Minquartia guianensis \\
\hline $66 a$ & Presencia de bandas & $67 a$ \\
\hline $66 b$ & Ausencia de bandas & $68 \mathrm{a}$ \\
\hline $67 a$ & Madera ligeramente rosada de peso moderado & Guarea grandifolia \\
\hline
\end{tabular}




\begin{tabular}{|c|c|c|}
\hline $67 \mathrm{~b}$ & Madera olivácea pesada de grano ondulado o entrecruzado & Terminalia oblonga \\
\hline $67 c$ & Madera amarillo rojiza de grano recto con tubos laticíferos & Virola koschnyi \\
\hline $67 d$ & Madera pesada amarillacon tílides en vasos del duramen & Xylopia sericophylla \\
\hline $67 e$ & Madera rojiza pesada de olor característico & Carapa guianensis \\
\hline $68 a$ & Parénquima vasicéntrico, aliforme y losangular, grano recto & Anacardium excelsum \\
\hline $68 \mathrm{~b}$ & Parénquima vasicéntrico, aliforme, losangular y unilateral & Poulsenia armata \\
\hline $68 c$ & Poros ovalados con radios finos muy abundantes y gomas & Sclerolobium costarricense \\
\hline $68 d$ & Madera amarilla de peso moderado con olor similar al mango & Bursera simaruba \\
\hline $69 a$ & Parénquima paratraqueal con bandas & $70 \mathrm{a}$ \\
\hline $69 b$ & Parénquima paratraqueal sin bandas & Abarema macradenia \\
\hline $70 \mathrm{a}$ & Madera café de peso moderado con gomas & Hymenolobium mesoamericanum \\
\hline $70 b$ & Parénquima aliforme y confluente con bandas finas discontinuas & Pterocarpus officinalis \\
\hline $70 c$ & Parénquima aliforme y confluente, madera amarilla y liviana & Simarouba amara \\
\hline $71 \mathrm{a}$ & Parénquima apotraqueal difuso o en agregados & $72 a$ \\
\hline $71 b$ & Parénquima paratraquealcon o sin bandas & $75 a$ \\
\hline $72 a$ & Parénquima apotraqueal difuso & $73 a$ \\
\hline $72 \mathrm{~b}$ & Parénquima apotraqueal difuso en agregados & $74 a$ \\
\hline $73 a$ & Madera café amarillento con veteado oscuro & Cordia alliodora \\
\hline $73 b$ & Parénquima vasicéntrico y aliforme Textura media a gruesa & Vochysia allenii \\
\hline $73 c$ & Madera amarilla pálida liviana Radios gruesos & Hampea appendiculata \\
\hline $73 d$ & Madera pesada con olor a pejibaye Bandas finas continúas & Maranthes panamensis \\
\hline $74 a$ & Madera amarilla pálido liviana, radios finos y gruesos & Ochroma pyramidale \\
\hline $74 b$ & Madera blanco oliváceo de peso moderado Radios finos y gruesos & Pachira aquatica \\
\hline $74 c$ & Madera amarillo pálido conradios muy visibles en cara tangencial & Sterculia recordiana \\
\hline $74 d$ & Madera amarilla pálida liviana Radios gruesos & Hampea appendiculata \\
\hline $74 \mathrm{e}$ & Madera pesada con olor a pejibaye Bandas finas continúas & Maranthes panamensis \\
\hline $75 a$ & Parénquima paratraqueal con bandas & $76 a$ \\
\hline $75 b$ & Parénquima paratraqueal sin bandas & Vochysia guatemalensis \\
\hline $76 a$ & Poros de escasa abundancia & $77 a$ \\
\hline $76 b$ & Poros de abundancia media & $78 a$ \\
\hline $76 c$ & Poros abundantes & $79 a$ \\
\hline $77 a$ & Parénquima vasicéntrico y losangular con bandas reticuladas & Erythrina poeppigiana \\
\hline $77 \mathrm{~b}$ & Madera amarillo pálido con bandas gruesas muy visibles & Ficus insipida \\
\hline $77 c$ & Parénquima aliforme y losangular con bandas gruesas & Jacaranda copaia \\
\hline $78 a$ & Parénquima vasicéntrico, aliforme, losangular y unilateral & Poulsenia armata \\
\hline $78 b$ & Madera amarillenta, peso moderado y poros múltiples 2 dominantes & Spondias monbin \\
\hline $78 \mathrm{c}$ & Madera rojiza con bandas finas reticuladas y escaleriformes & Vochysia ferruginea \\
\hline $79 a$ & Parénquima vasicéntrico, aliforme, losangular y unilateral & Poulsenia armata \\
\hline $79 b$ & Madera café amarillenta con porosidad con tendencia diagonal & Balizia elegans \\
\hline
\end{tabular}




\section{Referencias}

Acosta, I. 1967. Descripción anatómica, propiedades físicas y algunos usos de 25 maderas de Costa Rica. Tesis Mag. Sc. Turrialba, CR, Instituto Interamericano de Cooperación para la Agricultura . 192 p.

ACTo (Área de Conservación Tortuguero, CR). 2006. Módulo institucional de evaluación de expedientes forestales. Reporte de especies autorizadas de 2007 hasta 2011. (correo electrónico). Guápiles, CR, ACTo. (Contacto: Laura Rivera, email: lalyriveraqui@gmail.com).

Bolaños, MR; Watson, CV. 1999. Mapa ecológico de Costa Rica (Zonas de vida). Vladimir Jiménez S. San José, CR, CCT (Centro Científico Tropical). 1 mapa. Escala 1:400000. Colores.

COPANT (Comisión Pan-Americana de Normas Técnica, BR). 1974. Descripción macroscópica, microscópica y general de la madera. São Paulo, BR, COPANT. 30:1-19. (Esquema 1).

Espinoza PN; León, W. 2001. Anatomía de la madera. Mérida, VE, Universidad de Los Andes, Consejo de Publicaciones y Consejo de Desarrollo Científico, Humanístico y Tecnológico. $397 \mathrm{p}$.

Gonzales, E. 2008. Identificación organoléptica y macroscópica de maderas comerciales. Eds. Moscoso, J; Barreto, E; Gutiérrez, C. Lima, PE, CITEmadera. 40 p.

Holdridge, LR; Poveda A, LJ. 1975. Árboles de Costa Rica. Palmas, otras monocotiledóneas arbóreas y árboles con hojas compuestas o lobuladas. San José, CR, Centro Científico Tropical. Vol. 1. 546 p.

IBAMA (Instituto Brasileiro do Meio Ambiente e dos Recursos Naturais Renováveis, BR). 1992. Normas e procedimentos em estudos de anatomia da madeira: angiospermas e gimnospermas. Brasília, BR, Diretoria de Incentivo à Pesquisa e Divulgação. 17 p. (Série Técnica, n¹5).

IAWA (International Association of Wood Anatomist, NL). 1989. Committee IAWA list of microscopic features for hardwood Identification. IAWA Bulletin 10(3):219-332.

Jaen Jara, BA. 1989. Manual para la identificación de algunas especies maderables amenazadas 0 en peligro de extinción en la Península de Osa, Costa Rica. Informe de Práctica de Especialidad, Bach. en Ing. Forestal. Cartago, CR, Instituto Tecnológico de Costa Rica. Escuela de Ing. Forestal. $90 \mathrm{p}$.

Llynch, AH; Gasson, PE. 2010. Index Xylarium 4. (en línea). Wakehurst, UK. Consultado 28 jul. 2012. Disponible en: http://www.kew.org/collections/wood-index/Index Xylariorum4.htm (Royal Botanical Gardens, Kew).

MAC CORPORATION. 1994. Munsell soil color charts. Macbeth Division of Kollmorgen Instruments Corporation. US, MAC CORPORATION. 35p.

MINAE (Ministerio del Ambiente y Energía, CR). 1997. Declara en veda total aprovechamiento de árboles en peligro extinción indicados en el presente decreto. Decreto Ejecutivo No 25700-MINAE. La Gaceta. Diario Oficial, San José, CR, Enero. 16:9-10. 119(11).
Mora, J; Román, I. 2006. Organización rural, desarrollo territorial y sostenibilidad ambiental en el Caribe de Costa Rica: el caso del Área de Conservación Tortuguero. Guápiles, CR, Proyecto COBODES. 88 p.

OET (Organización para Estudios Tropicales, CR). 2004. La Flora Digital de La Selva. (en línea). Sarapiquí, CR. Consultado 16 jul. 2012. Disponible en http://sura.ots.ac.cr/local/ florula3/index.htm

SINAC (Sistema Nacional de Áreas de Conservación, CR). 2011. SINAC en números: Informe Década Estadísticas SEMEC 2000-2009. Comp. B Pavlotzky. San José, CR, SINAC. $128 \mathrm{p}$.

Wiemann, MC. 1987. Claves para la identificación de algunas maderas de Costa Rica. Turrialba 37(4):381-403.

Zamora V, N; Jiménez M, Q; Poveda A, LJ. 2003. Árboles de Costa Rica. Trees of Costa Rica. Santo Domingo, CR, INBIO (Instituto Nacional de Biodiversidad). Vol. 3. 556 p. 


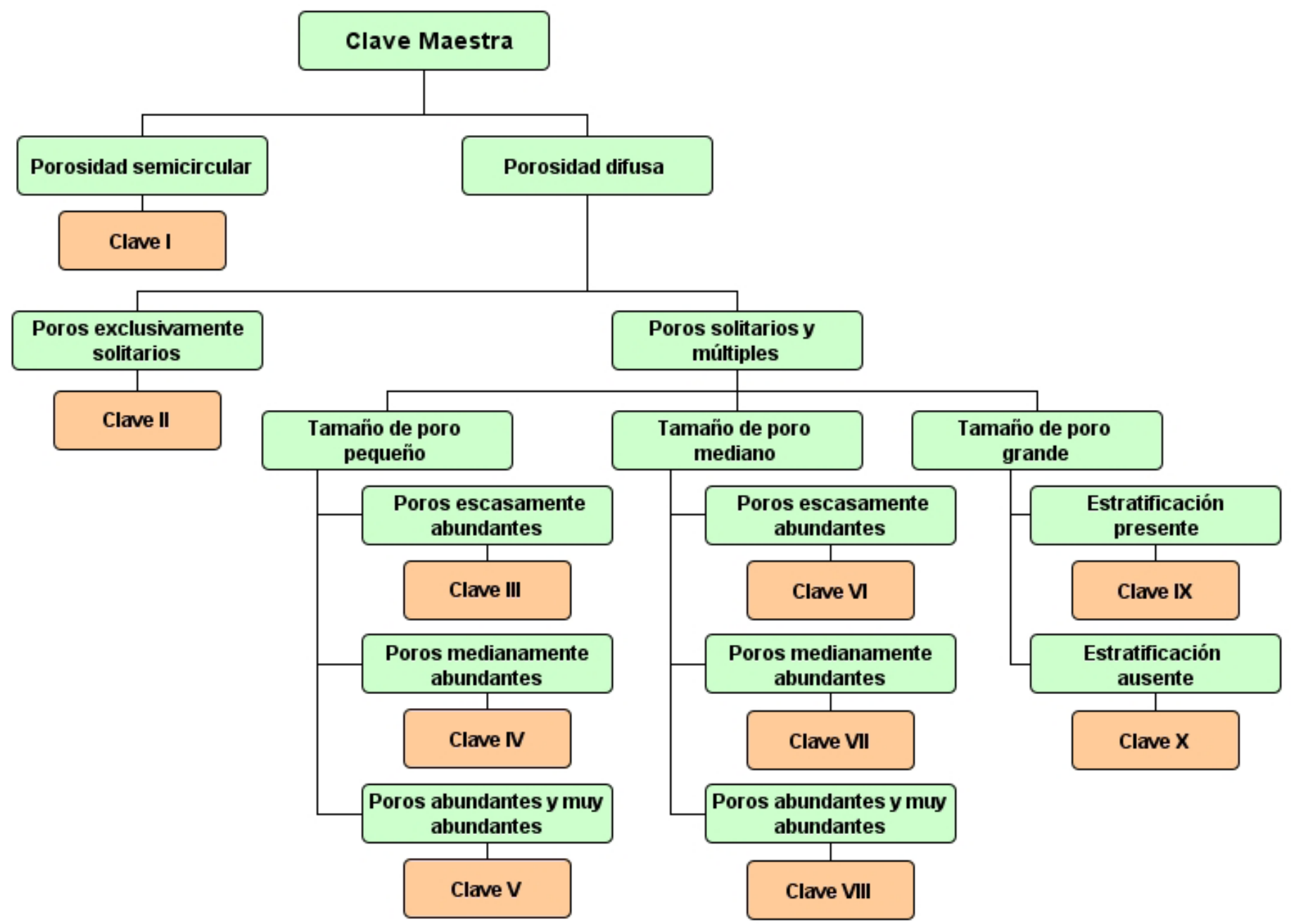

Figura 1. Esquema general de la clave de identificación macroscópica de la madera

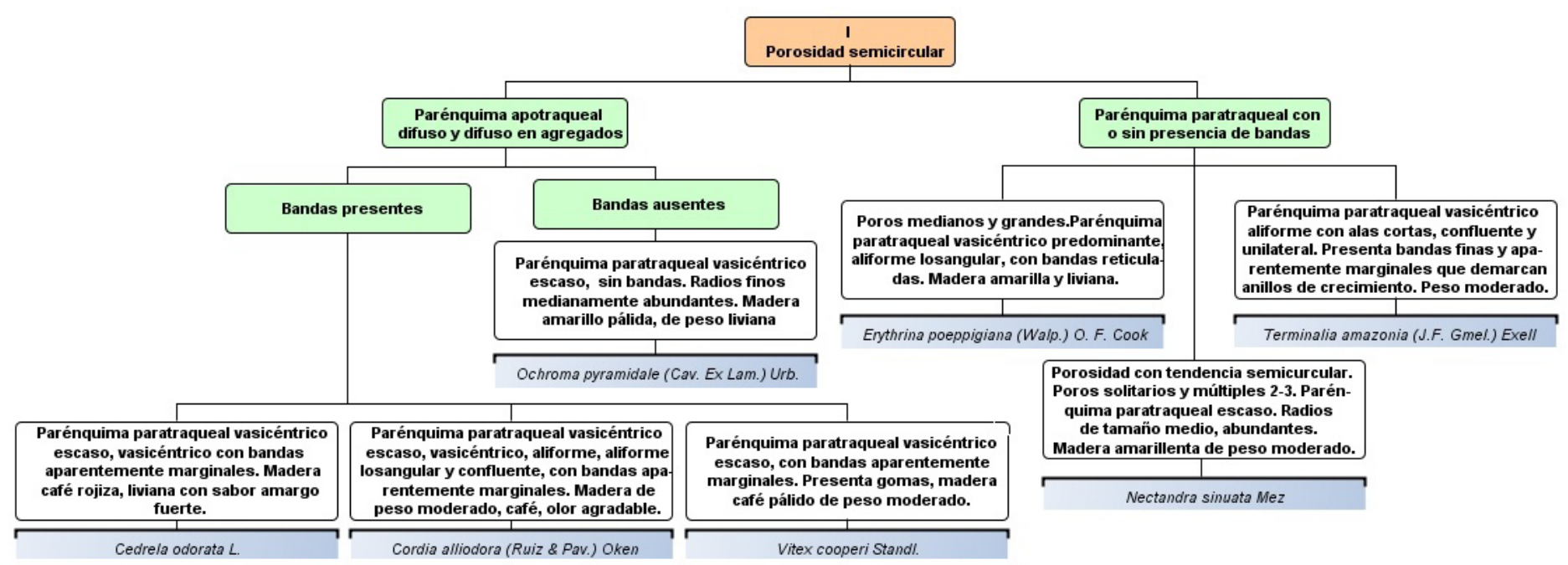

Figura 2. Esquema de identificación para las especies con porosidad semicircular (Clave I) 


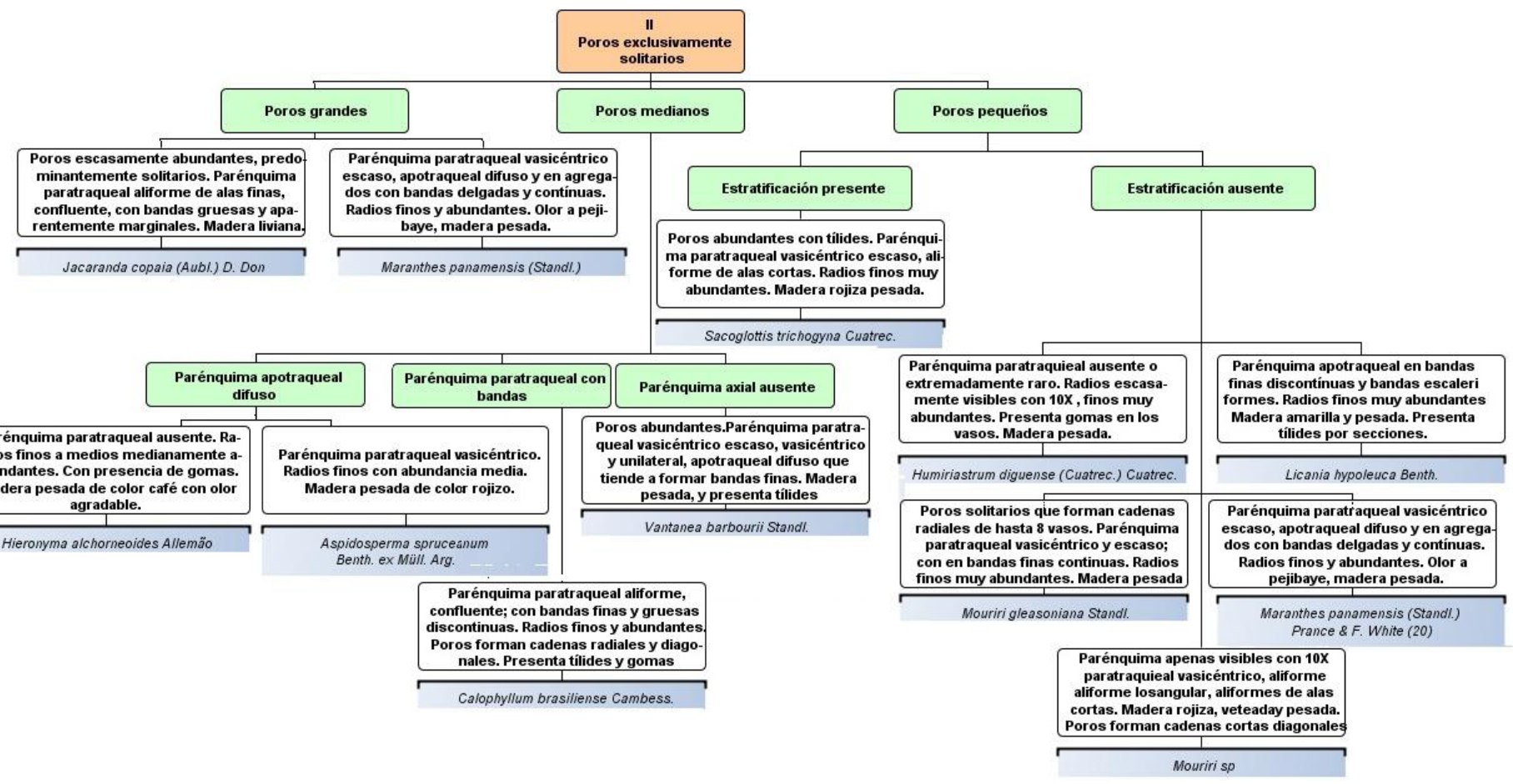

Figura 3. Esquema de identificación para las especies con poros exclusivamente solitarios (Clave II)

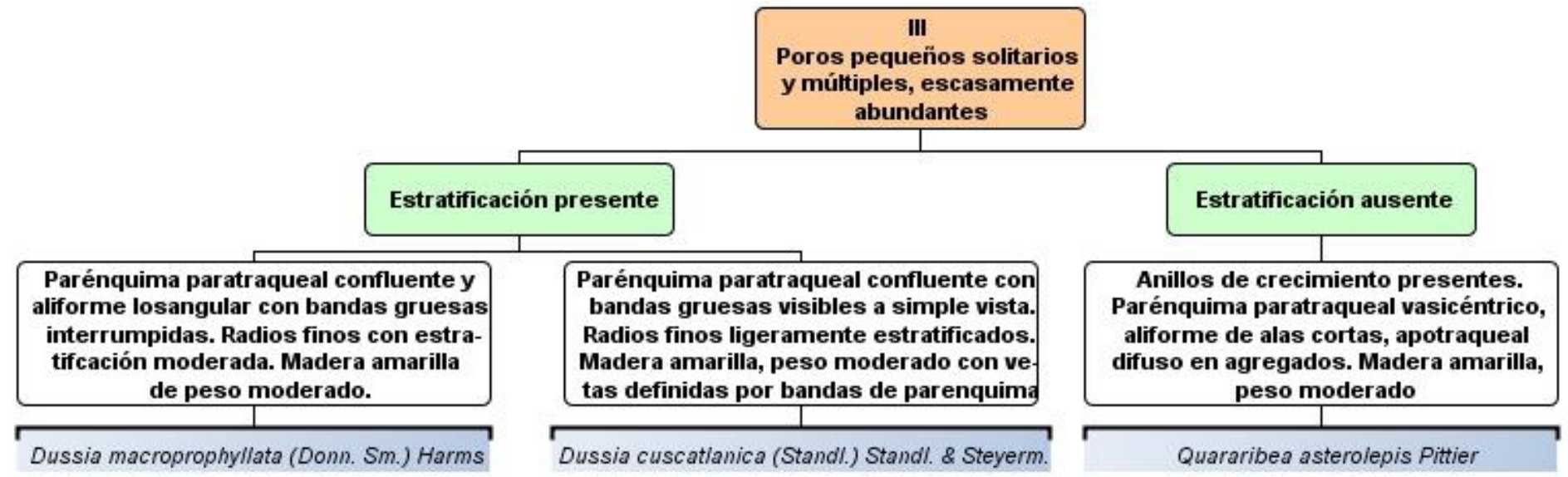

Figura 4. Esquema de identificación para las especies con poros pequeños, solitarios y múltiples, escasamente abundantes (Clave III) 


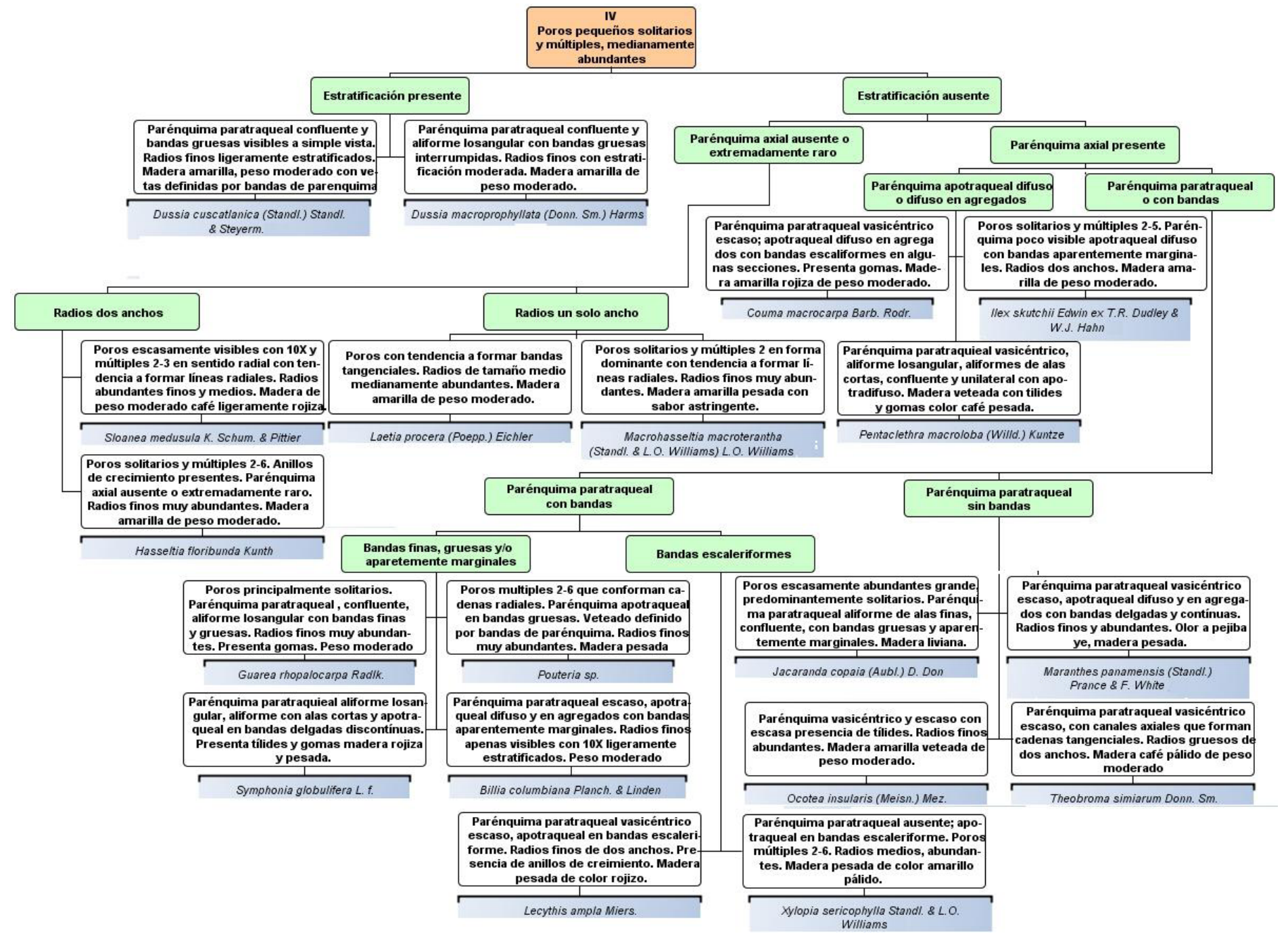

Figura 5. Esquema de identificación para las especies con poros pequeños, solitarios y múltiples, medianamente abundantes (Clave IV) 


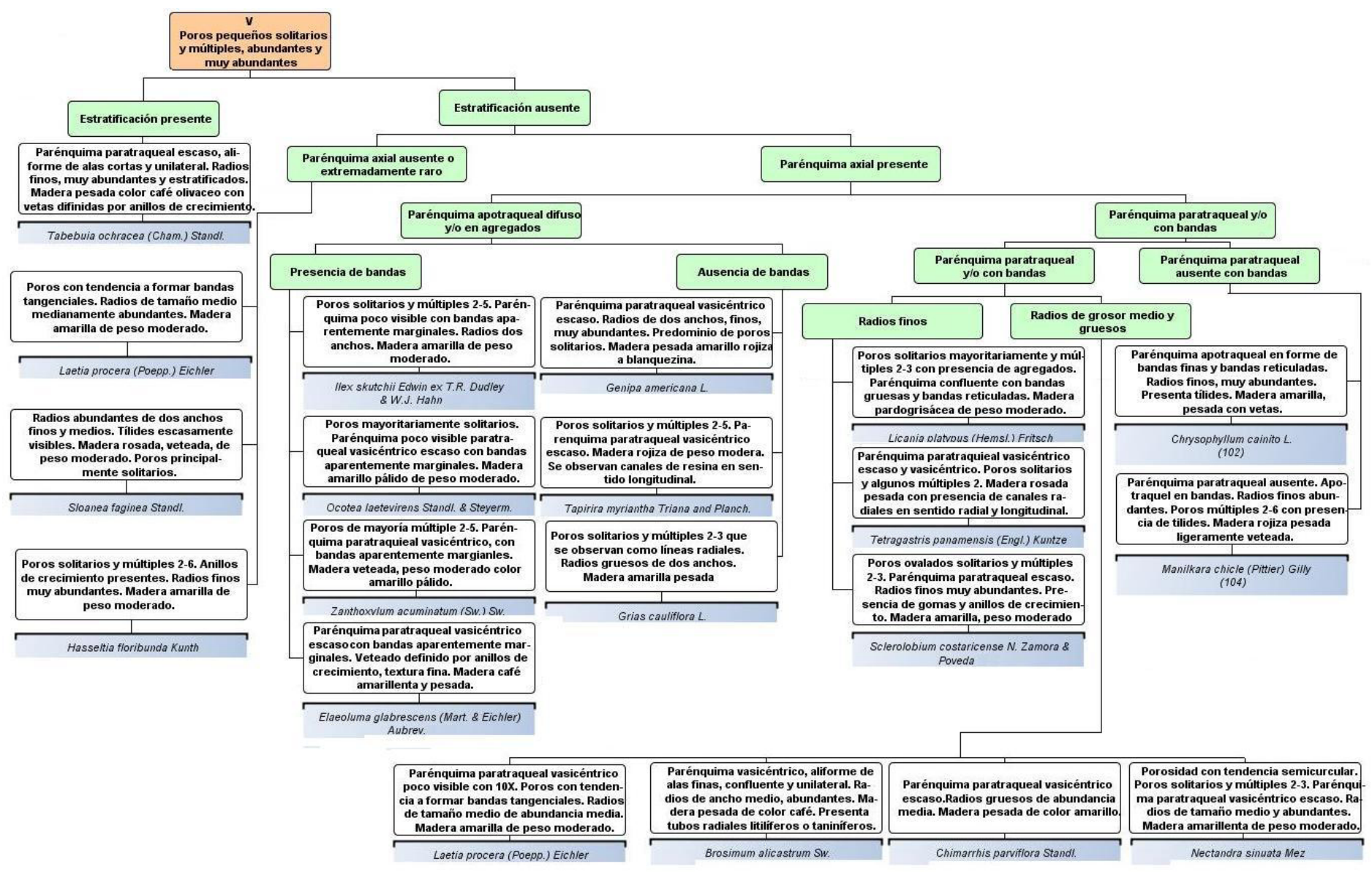

Figura 6. Esquema de identificación para las especies con poros pequeños, solitarios y múltiples, abundantes y muy abundantes (Clave V)

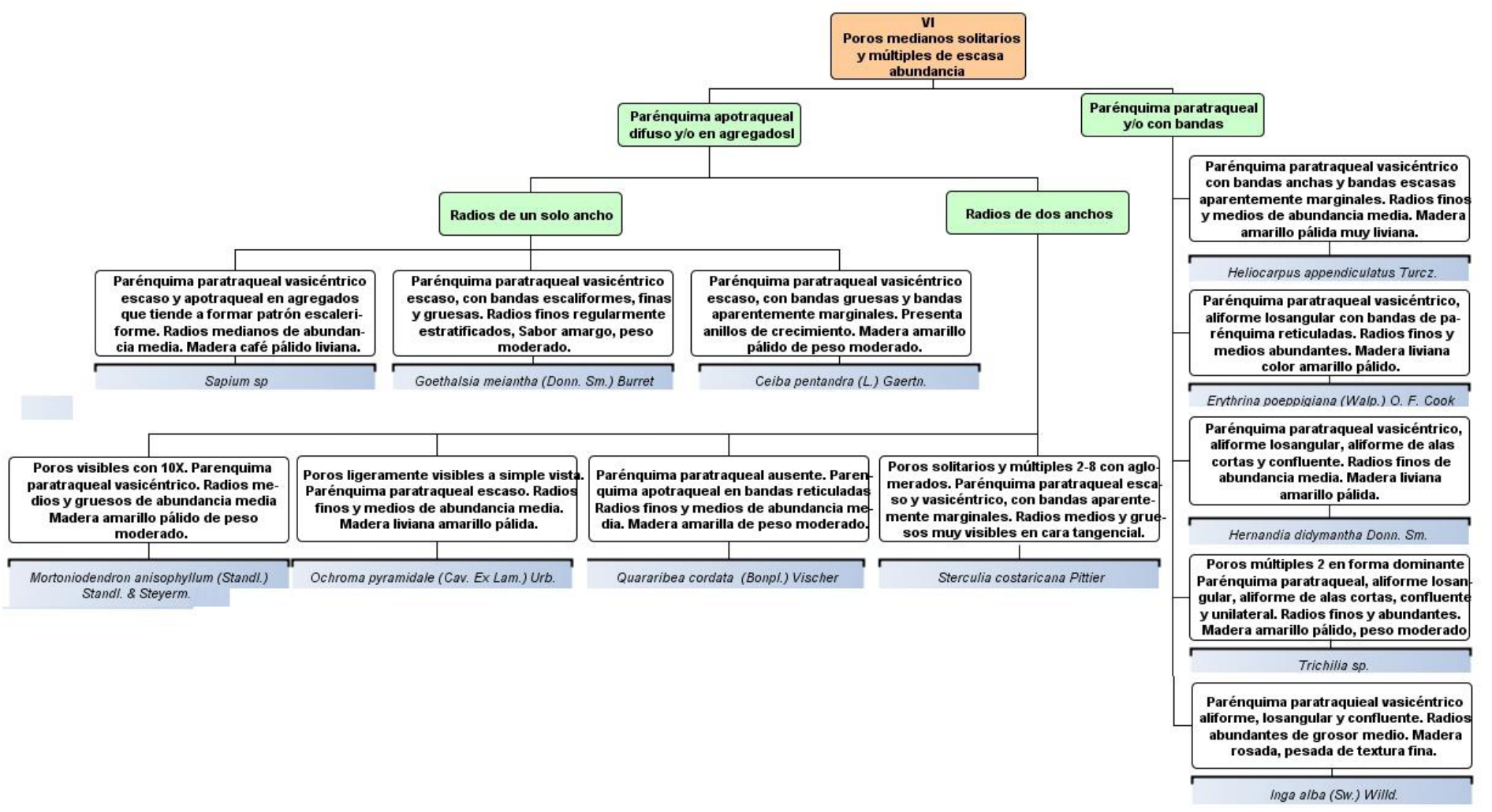

Figura 7. Esquema de identificación para las especies con poros medianos, solitarios y múltiples, escasamente abundantes (Clave VI) 


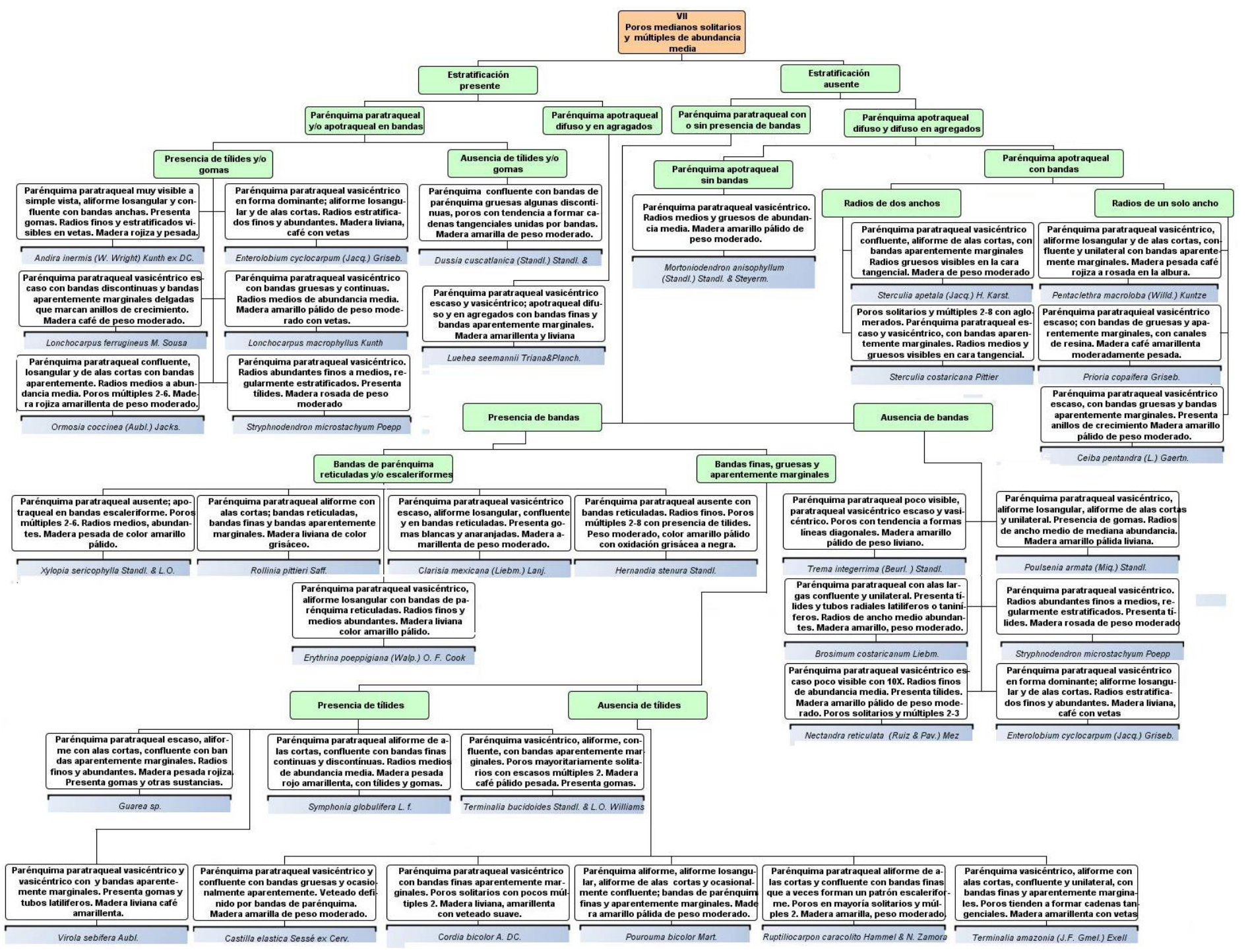

Figura 8. Esquema de identificación para las especies con poros medianos, solitarios y múltiples, de mediana abundancia (Clave VII) 


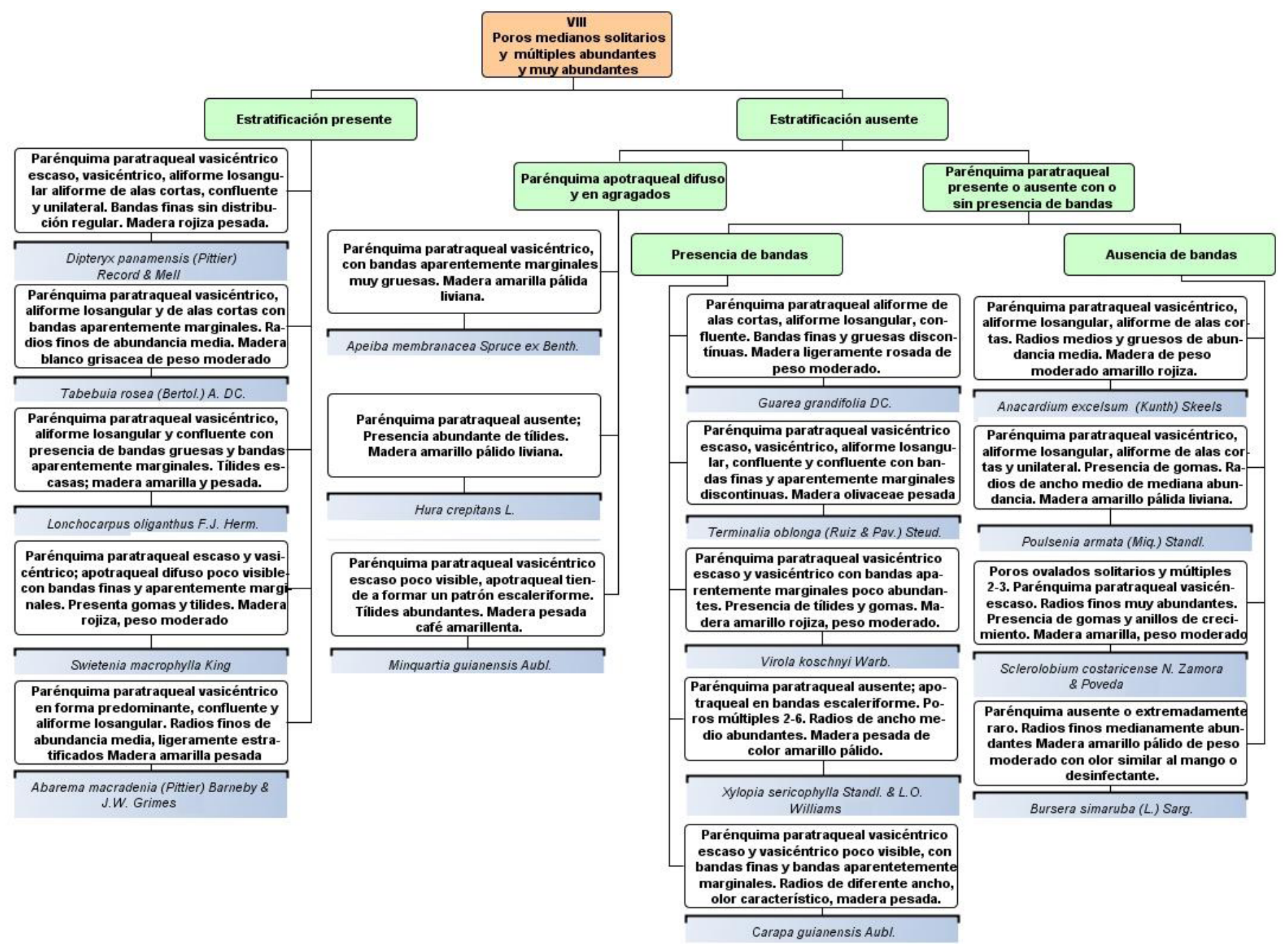

Figura 9. Esquema de identificación para las especies con poros medianos, solitarios y múltiples, abundantes y muy abundantes (Clave VIII).
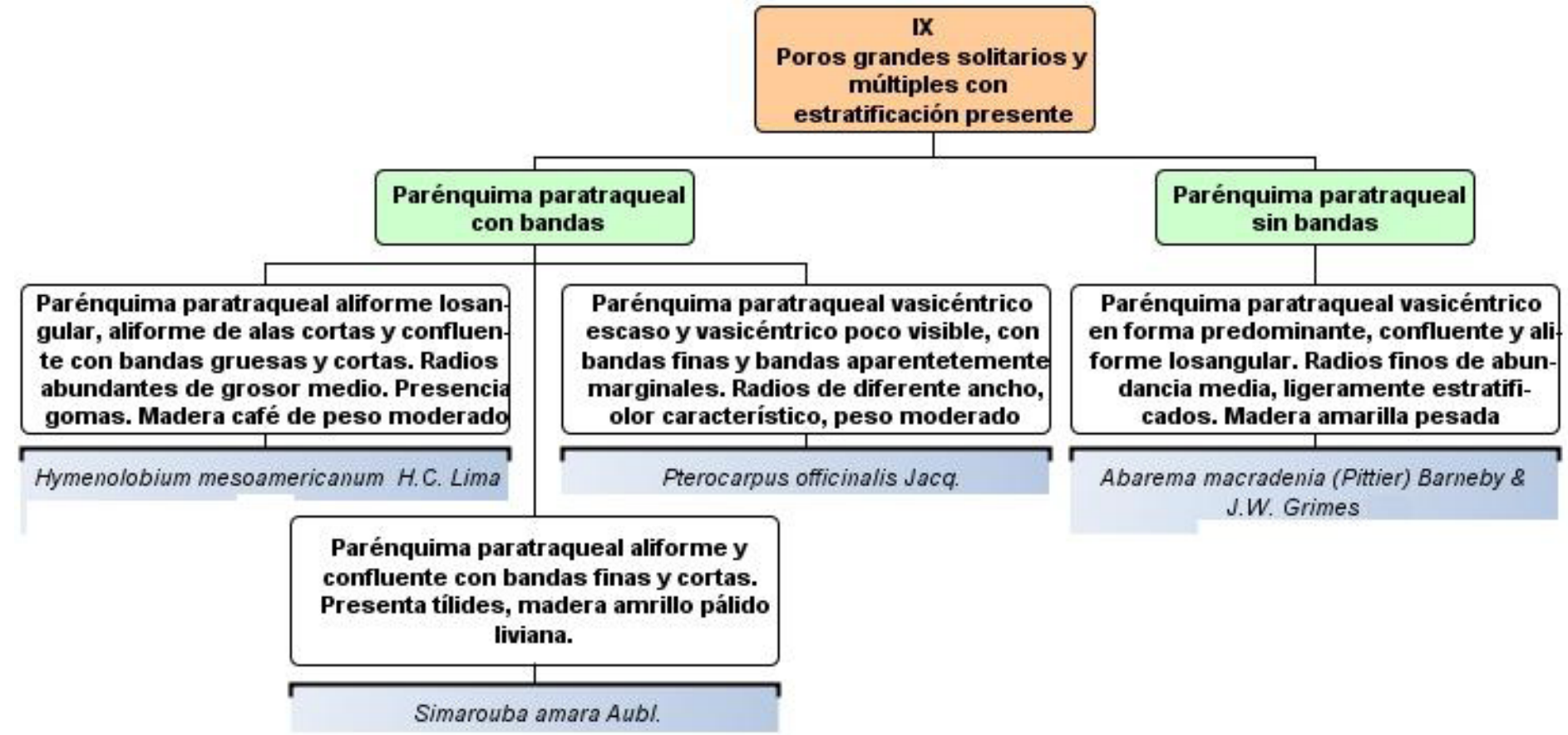

Figura 10. Esquema de identificación para las especies con poros grandes, solitarios y múltiples, con estratificación presente (Clave IX). 


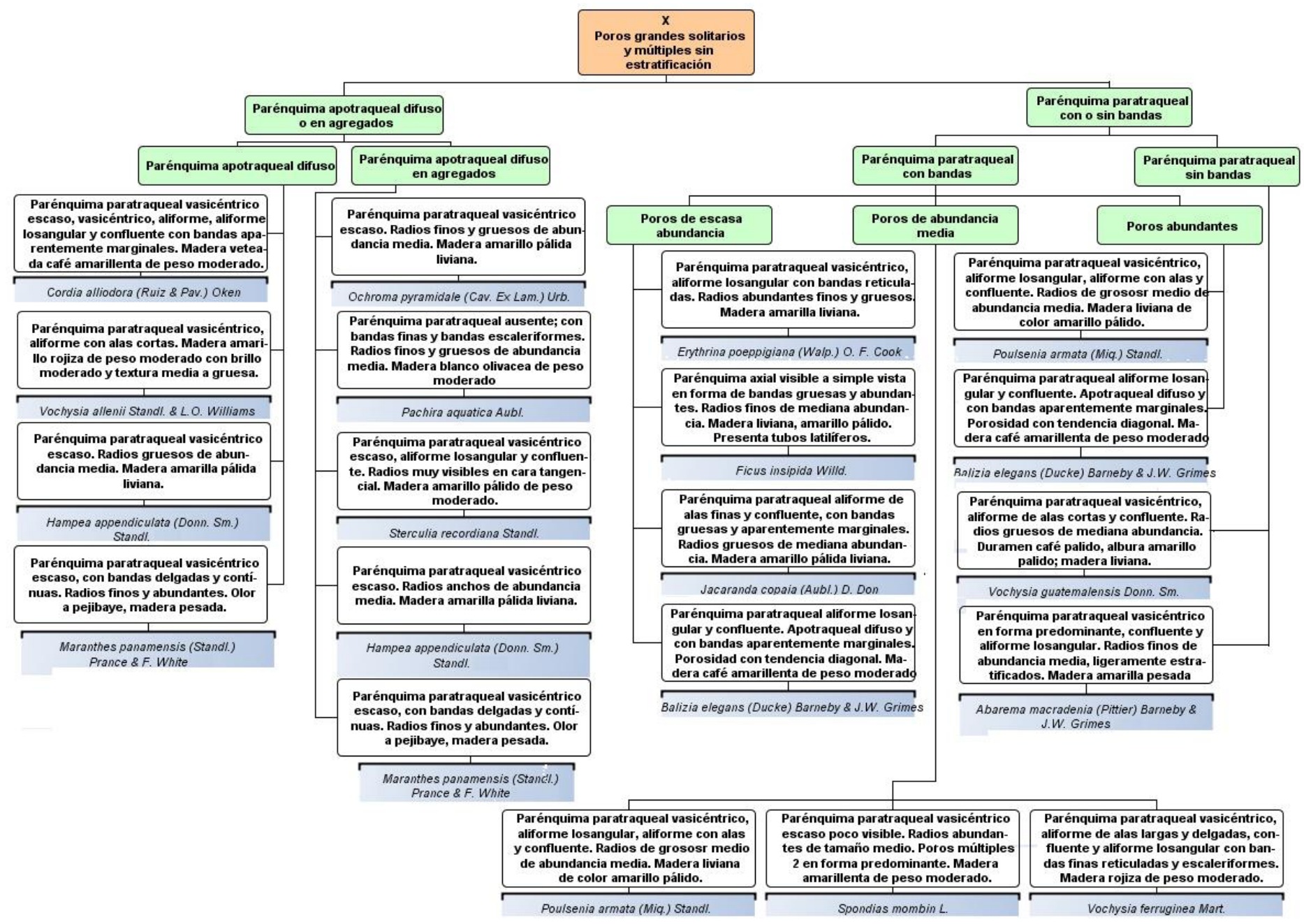

Figura 11. Esquema de identificación para las especies con poros grandes, solitarios y múltiples, sin estratificación (Clave X) 